\title{
iASeq: integrating multiple chip-seq datasets for detecting allele-specific binding
}

\author{
Yingying Wei ${ }^{1}$, Xia Li ${ }^{2}$, Qianfei Wang ${ }^{2}$, Hongkai ji ${ }^{*}$ \\ From Eighth International Society for Computational Biology (ISCB) Student Council Symposium 2012 \\ Long Beach, CA, USA. 13-14 July 2012
}

\section{Background}

ChIP-seq provides new opportunities to study allelespecific protein-DNA binding (ASB). Detecting ASB from ChIP-seq often suffers from low statistical power since only sequence reads mapped to heterozygote SNPs are informative for allelic inference. Moreover, little is known about the correlation patterns of ASB among different transcription factors and histone modifications.

\section{Methods}

We address both issues by developing iASeq to jointly analyze multiple ChIP-seq datasets. iASeq uses a Bayesian hierarchical model to automatically discover correlation patterns of ASB among multiple proteins. It then uses this correlation to borrow information across datasets to improve ASB detection.

Application of iASeq to 57 ENCODE datasets consisting of 117 ChIP-seq samples from GM12878 cells discovers synergistic allele-specificity patterns across different proteins. The analysis also shows the ability of iASeq to increase the power of ASB detection compared with the traditional approach which analyzes each individual dataset separately. According to two gold standards, iASeq's increased the accuracy of identifying ASB substantially.

\section{Conclusions}

iASeq demonstrates the value of integrating multiple datasets in the analysis of ASB, and it offers a new tool to better characterize allele-specificity. A user friendly $\mathrm{R}$ package is made available for iASeq. In principle, the same model can be applied to call allele-specific expression and allele-specific methylation by integrating multiple RNA-seq and MeDIP-seq studies.

* Correspondence: hji@jhsph.edu

${ }^{1}$ Johns Hopkins University, Baltimore, Maryland, USA

Full list of author information is available at the end of the article

\section{Author details}

${ }^{1} J o h n s$ Hopkins University, Baltimore, Maryland, USA. ${ }^{2}$ Beijing Institute of Genomics, Chinese Academy of Sciences, No.7 Beitucheng West Road, Chaoyang District, Beijing 100029, PR China.

Published: 14 December 2012

doi:10.1186/1471-2105-13-S18-A6

Cite this article as: Wei et al:: iASeq: integrating multiple chip-seq datasets for detecting allele-specific binding. BMC Bioinformatics 201213 (Suppl 18):A6.
Submit your next manuscript to BioMed Central and take full advantage of:

- Convenient online submission

- Thorough peer review

- No space constraints or color figure charges

- Immediate publication on acceptance

- Inclusion in PubMed, CAS, Scopus and Google Scholar

- Research which is freely available for redistribution
() Biomed Central 